


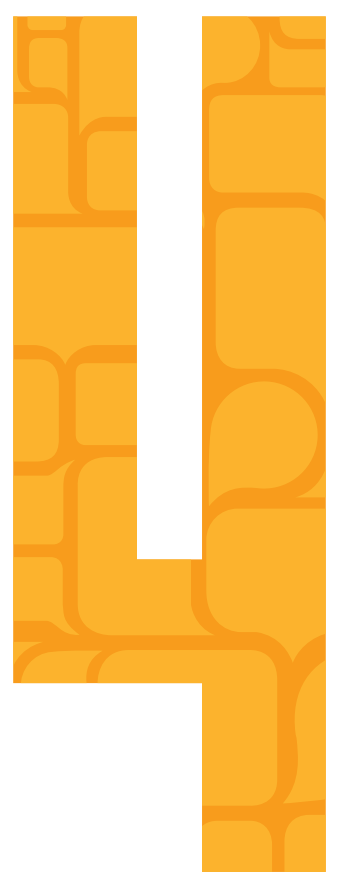




\section{Metodologias: como elaborar projetos expográficos}

Como visto no capítulo 2 no que tange os conceitos de expografia, elaborar projetos expográficos não é uma tarefa fácil. Para a concepção da exposição, esta deverá conter uma equipe multidisciplinar de forma que todas as áreas envolvidas no projeto possam ser bem trabalhadas.

Não é uma tarefa fácil, porém há alguns passos básicos que devem ser seguidos para a boa elaboração e montagem de um projeto expográfico.

Como afirma ARAUJO (apud TEIXEIRA22, 2005, p.7):

... a concepção e montagem de uma exposição, ou seja, a passagem do nível conceitual para o nível prático, implica no acompanhamento de um diálogo entre os objetos, os espaços, as cores, a luz, as linguagens de apoio e a visualização do público potencial. Esse diálogo que, invariavelmente, leva à delimitação, seleção, triagens, possibilita, também a geração, a partir de um saber constituído, da elaboração (para o público) de imagens, saberes e valores.

Dessa forma, o conjunto de elementos contidos na exposição deverão ser acompanhados de perto, bem como o público que deve receber atenção especial por ser um dos pilares do projeto expográfico.

Para podermos relatar os métodos de elaboração de exposições, devemos ressaltar que existem diversas maneiras de se montá-la e os métodos seguem princípios básicos e comuns entre si, diferenciando-se por pequenas variações. Serão esses princípios básicos que nortearão a pesquisa adiante.

Antes de partir para a parte prática da concepção da exposição, devem-se pensar os temas e recortes a serem utilizados para o projeto expográfico. "É traçado um mapa cognitivo com temas gerais e específicos, prioritários e secundários com relação de interdependência e/ou hierarquia. Esses temas e recortes serão tratados em exposições e educação" (CURY 2008, p.7). É nesse momento onde selecionamos o conteúdo a ser levado ao público.

Esses temas são pensados visando exposições a curto, médio e longo prazo para que todos os detalhes de comunicação e ações de marketing possam ser feitas.

Após essa etapa de seleção e delimitação do tema, propõe-se que seja feita a divisão de tarefas e principalmente quem será o responsável pela tomada de decisões

22 Graça Teixeira é Museóloga e professora assistente do curso de Museologia da UFB. Mestre em História da Arte e Doutoranda em História - UFB. 
dentro do grupo. Isso é de extrema importância para o bom andamento do cronograma de elaboração da exposição. Existem três métodos de tomadas de decisão: o método autocrático onde somente pessoas delegadas podem tomar as decisões pelo grupo, 0 método em equipe onde se faz a reunião de todos os profissionais a fim de tomarem as decisões de forma coletiva e, por fim, o método participativo onde, além dos profissionais, o sujeito - pertencente ao público-alvo da exposição - também participa dos debates expondo seu ponto de vista. Após esse processo partimos para o processo de concepção e montagem da exposição seguindo 5 fases fundamentais descritas por CURY (2008, p.22):

- 1. Planejamento de ideias

- 2. Desenho

- 3. Elaboração técnica

- 4. Montagem

- 5. Manutenção, atualização e avaliação

A primeira fase corresponde à definição da proposta central da exposição, que tipo de exposição pretende-se montar e quais estratégias e métodos de trabalho serão adotados. Ainda nessa fase serão definidos os objetivos, justificativas, o tema, estimativa orçamentária e o cronograma.

Na segunda fase a parte de estudos, conceituação, preparação e apresentação da forma e circuito da exposição serão trabalhadas e discutidas. Esses estudos gerarão aperfeiçoamentos na planta do espaço expositivo e preparação de maquetes de estudo.

A terceira fase compreende as ferramentas técnicas e executivas que serão adotadas para a instalação do espaço expositivo. Nessa fase deverá ser elaborado um guia de montagem da exposição que compreenda todas as instalações e a forma como devem ser confeccionadas.

A fase quatro é a de produção e instalação no espaço físico expositivo. É nesse momento que a exposição começa a tomar forma e sair do papel efetivamente.

Na quinta fase, com a exposição finalizada e já aberta ao público, caberá a manutenção da qualidade visual, a avaliação do processo e pesquisa de recepção com o usuário da exposição. Esse feedback é muito importante para que se possa entender se o conteúdo da exposição foi bem absorvido pelo público e se a exposição atingiu os objetivos propostos e planejados na fase um.

Esses são os métodos para a concepção de exposições, que focam num estudo profundo do objeto a ser exposto e no conteúdo da exposição muito mais do que na montagem propriamente difa. Seus métodos visam a pré e pós-produção em detrimento da produção. 
Continuando na linha de metodologias, Maria Ignez Mantovani Franco ${ }^{23}$ (2008, p.18) descreve o método de processo, planejamento e gerenciamento de exposições começando por quatro perguntas básicas: $O$ quê, por quê, para quem e com quê.

A pergunta referente ao "o quê" propõe-se que se responda qual a "história" que se quer contar. "Por quê" deverá justificar o tema, qual sua relevância e pertinência. "Para quem" define-se o público-alvo beneficiado pela exposição. Por último, "com quê", deverá ser respondido levantando os recursos disponíveis e possíveis de serem utilizados no projeto que irão desde pesquisas de fundamentação, elementos expositivos, recursos financeiros, materiais e humanos a parcerias e apoios.

Com base nessas respostas deverá ser traçada a estratégia para a elaboração da exposição que compreendem: metodologia, gestão, planejamento e cronograma, recursos humanos, orçamento e avaliação. Essas etapas devem ser seguidas visando a elaboração do produto final (exposição).

Um ponto crucial que Franco destaca em seu texto é a preocupação com a itinerância da exposição. Todos os detalhes de logística e de cuidados com os objetos devem ser tomados para que a exposição possa ser levada de um local á outro sem qualquer tipo de dano.

Segundo FRANCO $(2008$, p. 18) "democratizar a cultura é um dos pontos altos dos programas de itinerância de exposições, mas é recomendável que nos certifiquemos de que tais ações estão corretamente dimensionadas para motivar diversos públicos, de diferentes países, regiões, locais e culturas."

Com isso, podemos concluir que ambas as metodologias possuem passos básicos que se constituem em delimitar o tema, escolher o público-alvo, delimitar qual tipo de exposição virá a ser (autocrática ou comunicativa), a seleção das ferramentas para a montagem, a montagem efetiva e a avaliação e retorno do público.

Dessa forma os passos sugeridos nesse tópico tornarão mais viáveis os caminhos de planejamento e execução para a concepção de uma exposição.

\subsection{Linguagens de leitura expográfica}

Existem diversos mecanismos e ferramentas para se confeccionar uma exposição. Os materiais são variados e caberá a equipe, ou ao coordenador, decidir quais os materiais que atingirão os objetivos propostos da exposição.

Como um dos objetivos dessa pesquisa é o estudo de exposições comunicativas, uma das técnicas que estão em maior evidência no mercado e nas exposições atuais é o 3D.

23 Graduada em Comunicação Social, com especialização em Museologia, cursou doutorado em História Social na Universidade de São Paulo, este não concluído. 
O 3D - abreviação para três dimensões - segundo a revista INFO EXAME (2010, p. 31) surgiv em 1838 com o cientista inglês Charles Wheatstone que criou o estereoscópio - dispositivo que permitia ver imagens tridimensionais.

Há diversas maneiras de se proporcionar o efeito óptico do 3D, porém o conceito básico advém da ilusão obtida pela distância entre nossos olhos. Cada um enxerga a mesma imagem por ângulos diferentes e isso proporciona o efeito de profundidade. Ao simularmos isso em um plano $2 \mathrm{D}$ - duas dimensões, como uma tela de cinema por exemplo - temos o efeito de profundidade característico do 3D.

A seguir, apresentaremos algumas técnicas que simulam esse tipo de efeito e outras que trabalham o efeito 3D de outra maneira e, que poderão ser aplicados no produto final desta pesquisa caso se adéquem aos objetivos propostos.

\subsubsection{Anaglífos}

Segundo o site E-escola, Instituto Superior Técnico (2007), os óculos anaglíficos foram inventados por volta de 1850 pelo físico português José Carlos de Almeida.

O efeito óptico proporcionado pelos óculos anaglíficos funciona da seguinte maneira: nossos olhos enxergam a mesma imagem por perspectivas diferentes, ou seja, o lado esquerdo enxerga a imagem mais desviada para a esquerda e o direito mais desviado para a direita. Com isso, ao duplicarmos a imagem em duas camadas diferentes, a direita em azul/verde e a esquerda em vermelho, quando colocamos os óculos cada olho irá ver a camada que é correspondente a sua cor, atuando como um filtro, e isso irá proporcionar o efeito de profundidade.

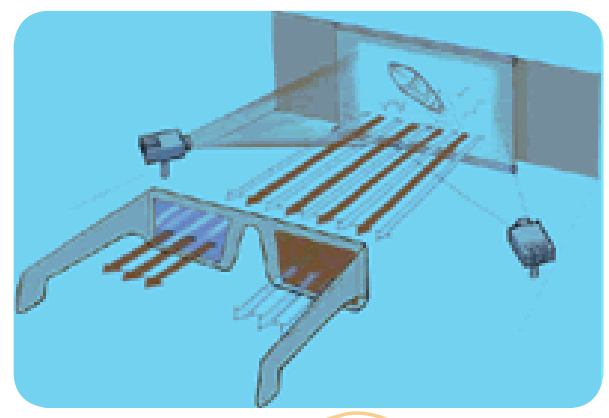

Figura 59. Modelo de como funciona um óculos anaglífico.

Fonte: http://www.e-escola.pt/destaques.asp?id=78
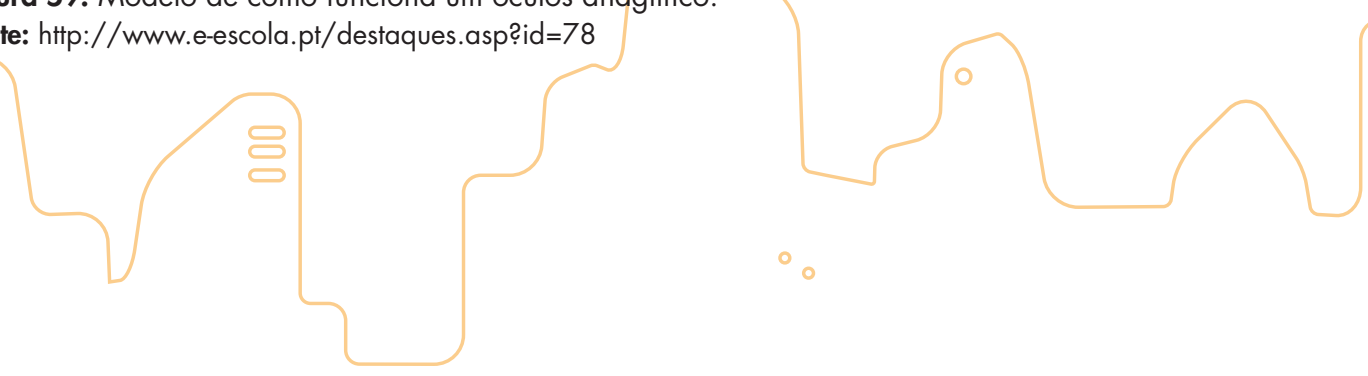


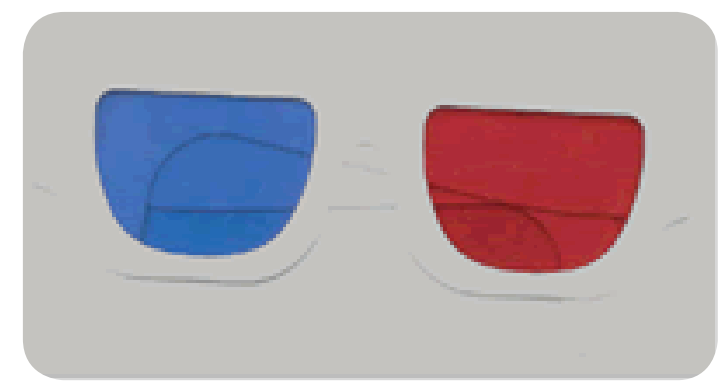

Figura 60. Exemplo de óculos anaglífico.

Fonte: http://www.e-escola.pt/destaques.asp?id=78.

Atualmente existem dois tipos de óculos para ver imagens em três dimensões: os ativos em os passivos. Segundo a revista INFO EXAME (2010, p.33):

Os passivos, comumente usados no cinema, se dividem em dois modelos: os anaglificos (em geral em azul e vermelho) filtram as imagens por cor, enquanto os polarizados fazem as separações por ondas na vertical e na horizontal. Já os ativos, que acompanham as TVs 3D e são mais caros, têm dois pequenos painéis de $L C D$ no lugar das lentes e, sincronizados por infravermelho, mostram as imagens alternadamente para cada olho.

Os óculos anaglíficos e polarizados possuem algumas limitações. À revista INFO EXAME (2010, p.34), Célia Nakonami, chefe de oftalmologia pediátrica da Universidade Federal de São Paulo, afirma só ser possível ver o efeito 3D quem possui os olhos alinhados. Pessoas com estrabismo, ambliopia (redução significativa ou perda da visão de um dos olhos) não podem ver o efeito 3D pelos polarizados e, quem possui daltonismo pode não notar o efeito pelos óculos anaglíficos.

\subsubsection{Anamorfose}

A técnica da anamorfose consiste em observar uma figura aparentemente distorcida com um espelho - este podendo ser quadrangular, cilíndrico ou piramidal dependendo da obra. Ao colocarmos o espelho no local correto da imagem, este refletirá a imagem focalizada da obra permitindo que se consiga decifrála.

Do Grego anamorphosis, Raul Mendes Silva ${ }^{24}$ (2010) afirma que:

24 Formado em Direito pela Faculdade de Direito da Universidade de Coimbra. Sócio-fundador do Círculo de Artes Plásticas e do Centro de Iniciação Teatral (Citac) da mesma cidade. Frequenta a Faculdade de Filosofia, na Universidade de Coimbra. 
Na história da pintura ocidental é mencionado um caso típico e célebre de anamorfose, o quadro Os embaixadores, do alemão Hans Holbein (1497-1543), pertencente à National Gallery, de Londres. Na parte de baixo da obra surge uma forma oblonga estranha. Quando observada do lado direito e bem perto do plano da tela, descobre-se que é uma caveira humana.

Segue abaixo uma reprodução do quadro Os embaixadores de Hans Holbein.
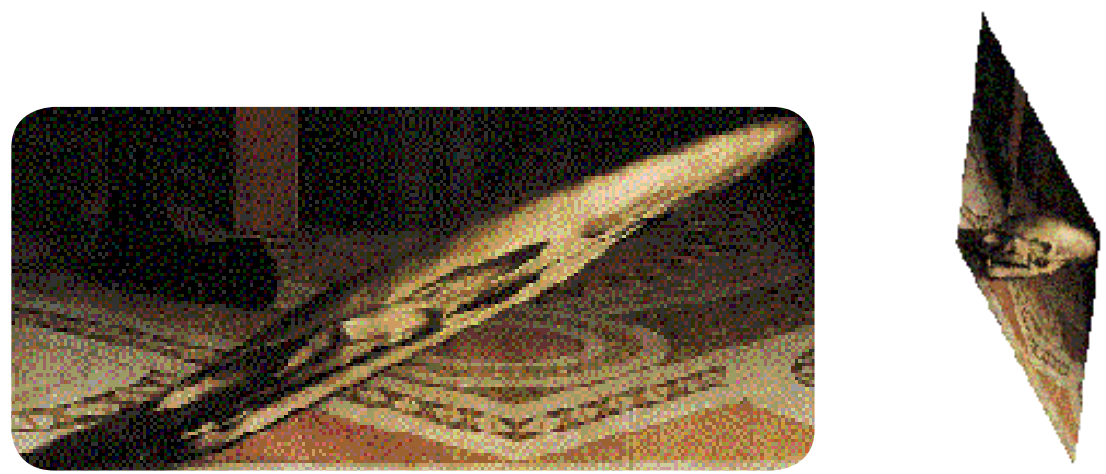

Figura 61. A figura acima mostra a imagem original distorcida no quadro de Holbein e a sua representação normalizada através do efeito de um espelho.

Fonte: http://wwwl .ci.uc.pt/iej/alunos/1998-99/cbs/entrada2/skull.gif

Na antiguidade a anamorfose servia como método para camuflar imagens de conteúdo político ou pornográfico.

Um exemplo típico da aplicação da anamorfose na atualidade são as sinalizações nas estradas, como por exemplo, as palavras escritas na pista. Quando olhadas por qualquer ângulo são esticadas, distorcidas, porém quando as vemos pelo ângulo correto, de dentro do automóvel, vemos as letras tomarem formas normais.

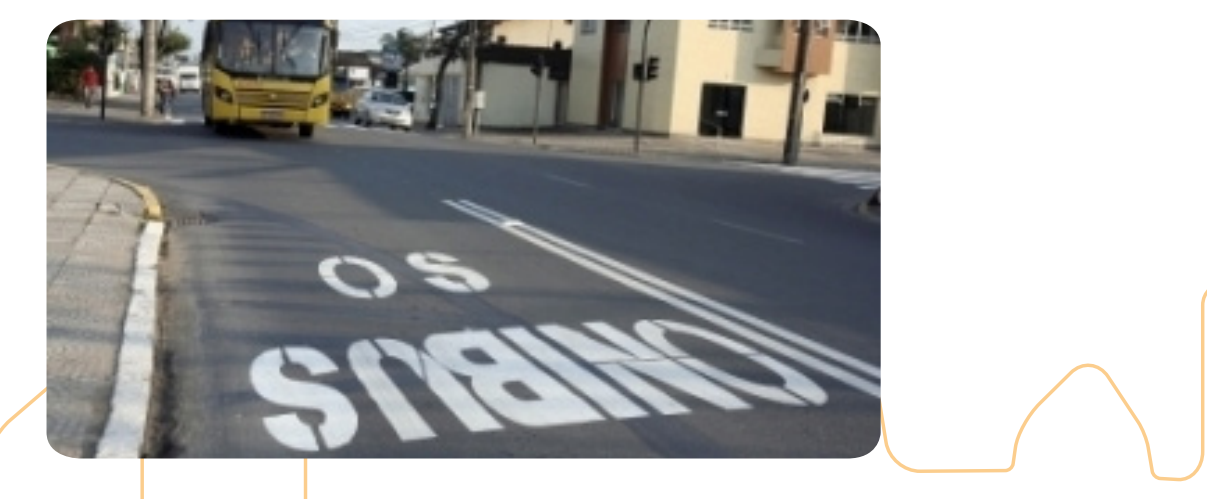

Figura 62. Exemplo de aplicação da anamorfose na pista.

Fonte: http://linux.alfamaweb.com.br/setransp/conteudo. php? $\mathrm{c}=186 \& \mathrm{~s}=586 \& \mathrm{ct}=32528 \& \mathrm{o}=1$ 


\subsubsection{Estereoscopia}

O termo "estereoscopia" engloba todas as técnicas que utilizam o mecanismo visual binocular do ser humano, para criarem uma sensação de profundidade em duas ou mais imagens bidimensionais do mesmo objeto representado por meio de diferentes perspectivas. A palavra "estereoscopia" deriva do grego "stereos"e "skopein", que significam, respectivamente, "sólido", "relevo" e "olhar", "ver", quer dizer, visão em relevo. A frequente interpretação de "estéreo" no sentido de "dois" é resultante do fato de necessitarmos de dois olhos e dois ouvidos para vermos e ouvirmos espacialmente. No fim do século passado e começo deste a estereoscopia atingiu grande divulgação como entretenimento e ainda hoje as inúmeras imagens estereoscópicas, que podemos encontrar em livrarias, atestam o fascínio que as mesmas exercem sobre as pessoas. As primeiras máquinas estereoscópicas, que possibilitaram uma simples imagem de estereograma, foram fabricadas logo a seguir à invenção da fotografia. Outros dispositivos necessários à observação de estereogramas usufruiram de um considerável aperfeiçoamento nesta época, criando-se, por exemplo, os óculos verde-vermelhos, ainda hoje muito divulgados. Porém, não é tão conhecida a possibilidade de produção de estereogramas, cuja observação dispense qualquer aparelho especial. No entanto, os auto-estereogramas que aqui serão apresentados apresentam uma particularidade: observados superficialmente, parecem uma composição de padrões dispostos apenas ao acaso e sem qualquer sentido. A imagem tridimensional só será identificada por meio de uma técnica de observação, cuja explicação será dada em "visualizando".

\subsubsection{Auto-estereogramas}

Os auto-estereogramas são imagens que, num primeiro momento não parecem fazer muito sentido, passando a sensação de pontos meramente aleatórios. Porém, utilizando-se de duas técnicas básicas é possível visualizar a imagem tridimensional contida do estereograma.

As técnicas de visualização dos auto-estereogramas são o Método Convergente e o Método Divergente, e foram extraídas do site www.estereomagia.com.br:

- MÉTODO CONVERGENTE: olhe para o estereograma, porém concentrando o sua visão em um objeto imaginário como se estivesse localizado há alguns metros atrás da tela. Permaneça nessa posição por algum tempo sem desviar o olhar dessa posição. Decorrido alguns instantes eis que, num dado momento, surge a figura em três dimensões, cuja imagem parece saltar do seu plano em direção aos olhos; 
- MÉTODO DIVERGENTE: em frente à figura, suspenda um lápis há aproximadamente $20 \mathrm{~cm}$ de distância do nariz e, olhando em direção à tela, concentre sua visão fixamente em sua ponta, permanecendo nessa posição por alguns instantes. Após alguns segundos, retire-o lentamente e eis que novamente surge a figura. É possível que consiga reconhecer imediatamente a imagem tridimensional mesmo sem as seguintes instruções.

É possível que se consiga visualizar a figura tridimensional contida nos estereogramas sem seguir esses métodos, eles servem apenas para facilitar e adaptar a visão do expectador para que ele alcance o resultado em menos tempo.

Porém, o site Estereomagia (2010) faz um alerta ao dizer que "é provável que tenha de esforçar-se durante meia hora ou mais, até aprender a técnica correta de olhar." (http://www.estereomagia.com.br/port/estereo.html acesso 19/05/2010 às 15:46) Ou seja, pode levar um certo tempo até que nossa visão focalize corretamente a figura tridimensional, mas conforme o treinamento dos métodos vai melhorando é bem provável que esse tempo diminua.

A seguir veremos alguns estereogramas e as imagens tridimensionais contidas que estão contidas neles.

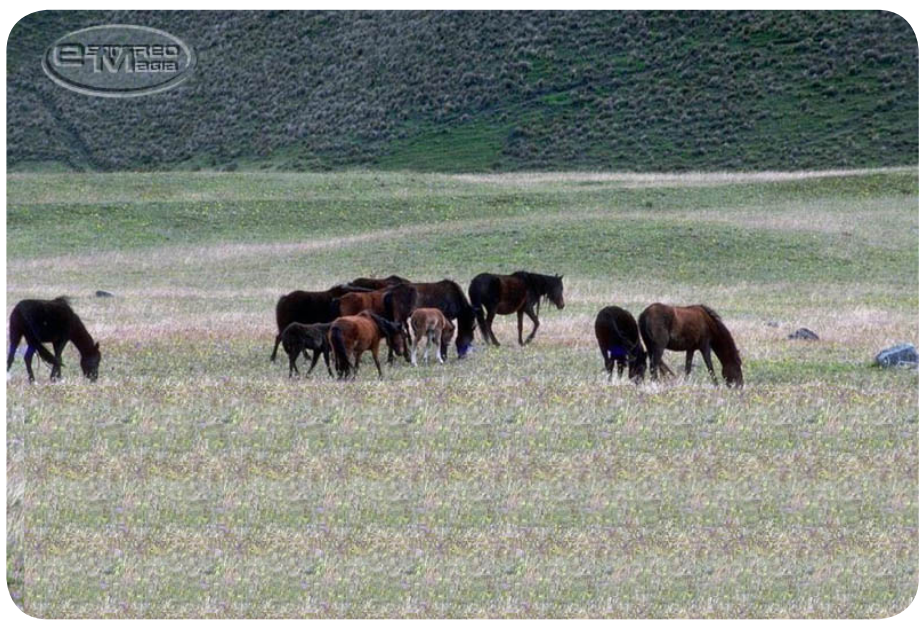

Figura 63. Estereograma que forma a figura de uma aranha

Fonte: http://www.estereomagia.com.br/port/cavalos.html acesso: 24/05/2010 às 12:20 


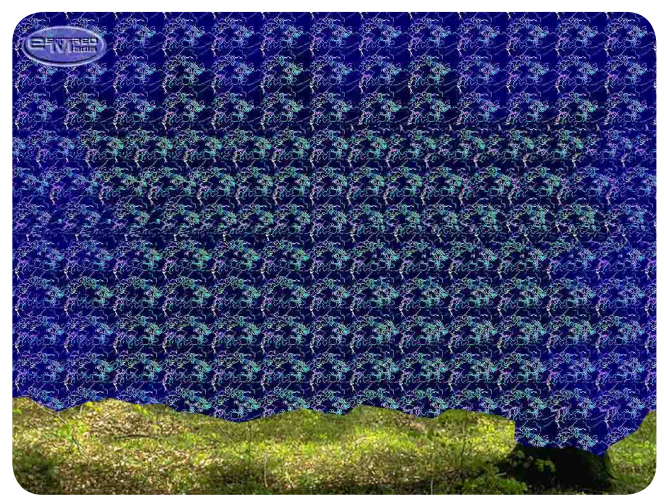

Figura 64. Estereograma que forma a figura de um cogumelo

Fonte: http://www.estereomagia.com.br/port/cogumeo.html acesso: 24/05/2010 às 12:22

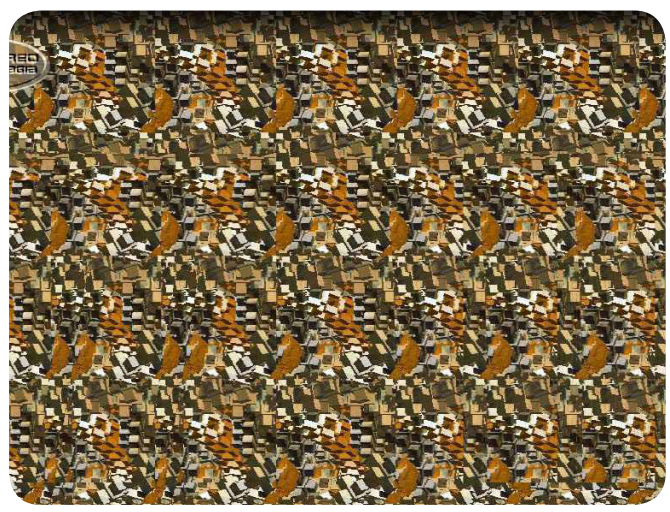

Figura 65. Estereograma que forma a figura de um atleta de hockey

Fonte: http://www.estereomagia.com.br/port/hokey.html acesso: 24/05/2010 às 12:26

Os estereogramas apresentados são mais bem visualizados e transmitem melhor a imagem tridimensional se estiverem em tamanho maior.

\subsubsection{D Style}

O 3D Style não é propriamente uma técnica de 3D que simula efeitos ópticos. Esta técnica, utilizada no graffiti, transforma letras chapadas em letras mais volumétricas e que passam a sensação de estarem saltando da parede. É uma técnica que leva um efeito realista de luz e sobra simulando volume e profundidade sem a necessidade de utilizar óculos. 
Esse tipo de técnica rompe com a bidimensionalidade do suporte utilizado e busca trabalhar os elementos de modo que pareçam estar vinculados ao suporte.

A seguir podemos visualizar a aplicação dessa técnica:

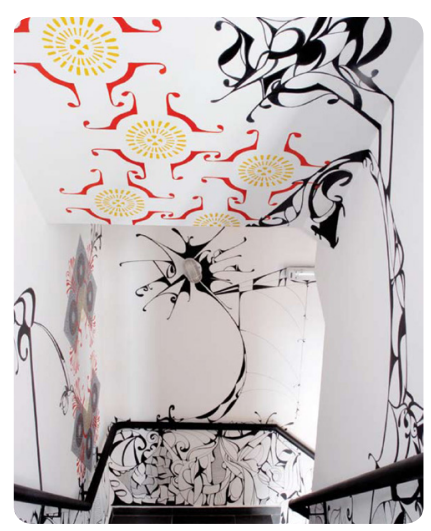

Figura 66. Aplicação de graffiti em parede.

Fonte: Catálogo JAMAC - Jardim Miriam Arte Clube 2007

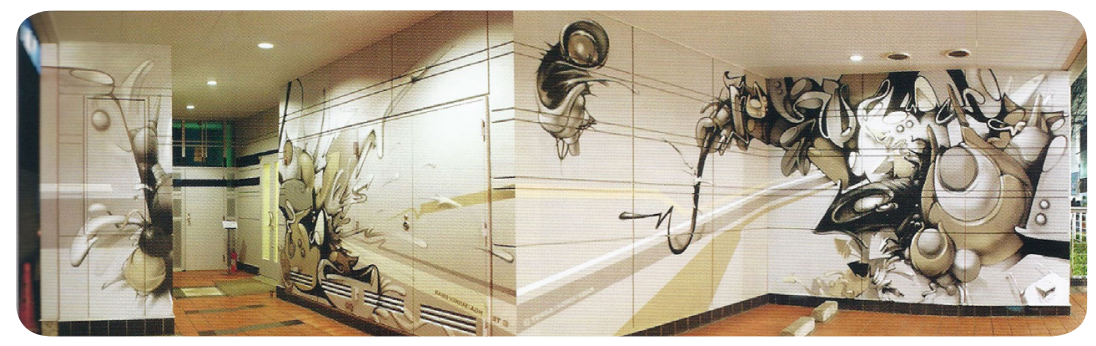

Figura 67. Aplicação da técnica do 3D Style.

Fonte: Revista Graffiti Japan 2008.

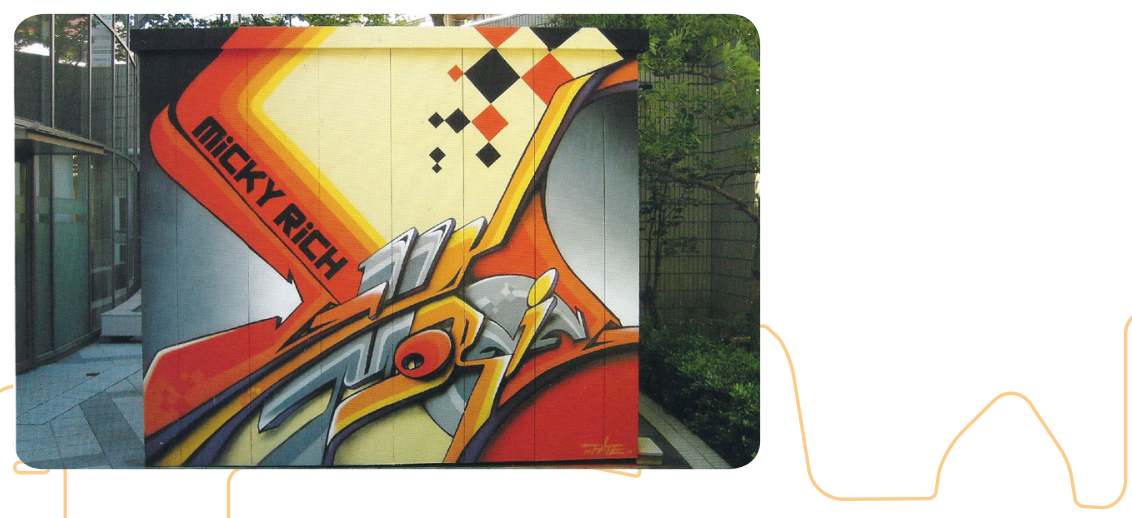

Figura 68. Aplicação da técnica do 3D Style.

Fonte: Revista Graffiti Japan 2008. 


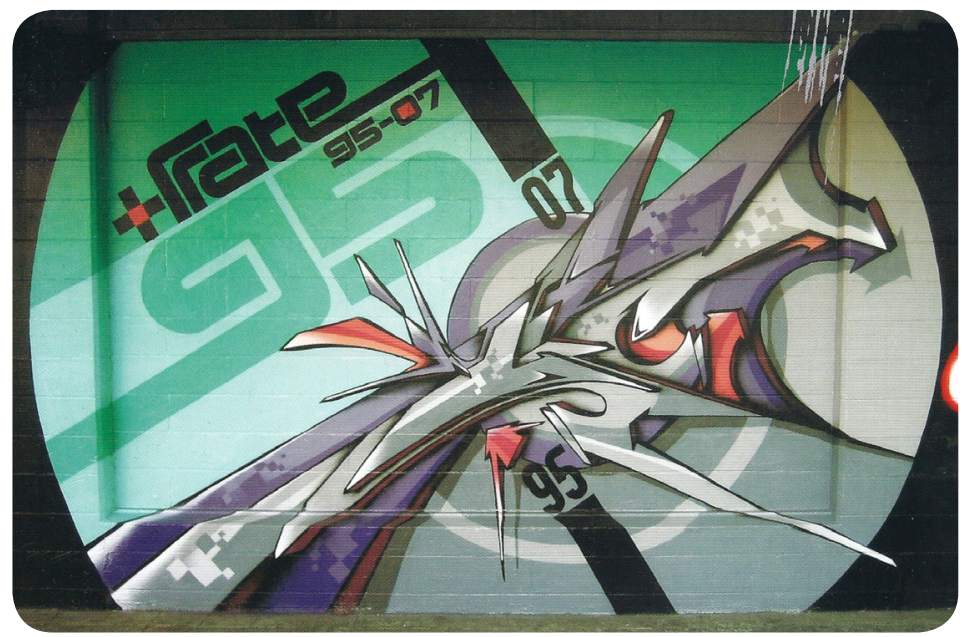

Figura 69. Aplicação da técnica do 3D Style.

Fonte: Revista Graffiti Japan 2008.

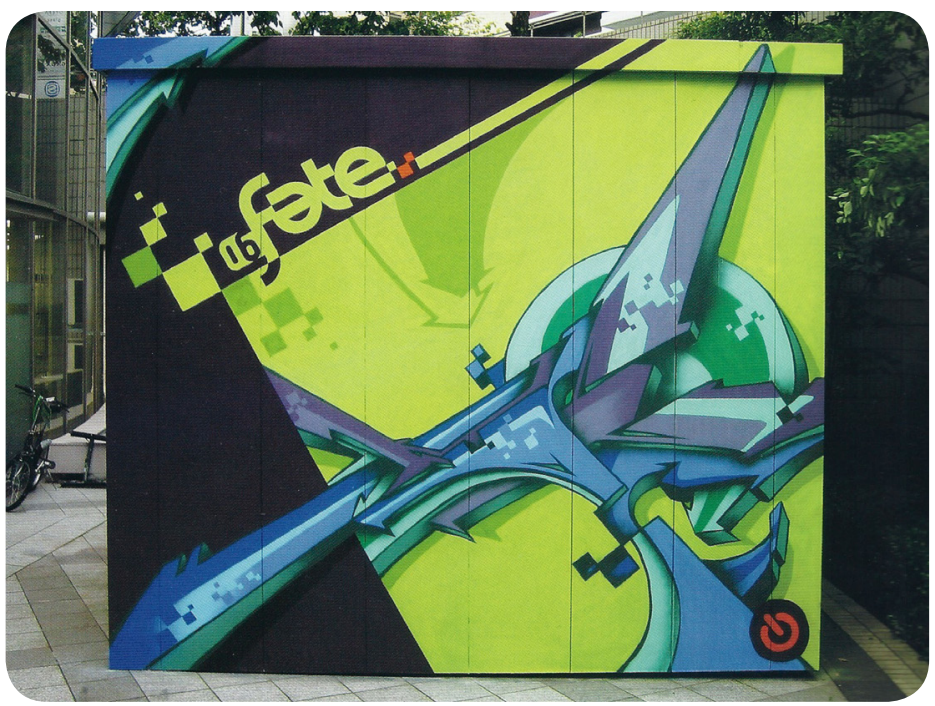

Figura 70. Aplicação da técnica do 3D Style.

Fonte: Revista Graffiti Japan 2008.

Após essa análise podemos perceber que os métodos de linguagens expográficas são muitos e sua aplicação dependerá muito dos objetivos do projeto final. A forma como esses elementos poderão ser aplicados nos objetos da exposição incorrerá na interação com o público de modo que a exposição comunicará de forma clara e interativa o conteúdo exposto. 
